\title{
Article \\ Generation of Iron-Independent Siderophore-Producing Agaricus bisporus through the Constitutive Expression of hapX
}

\author{
Min-Seek Kim and Hyeon-Su Ro *(D) \\ Department of Bio \& Medical Big Data and Research Institute of Life Sciences, Gyeongsang National University, \\ Jinju 52828, Korea; kmstaur@gmail.com \\ * Correspondence: rohyeon@gnu.ac.kr; Tel.: +82-55-772-1328
}

Citation: Kim, M.-H.; Ro, H.-S. Generation of Iron-Independent Siderophore-Producing Agaricus bisporus through the Constitutive Expression of hapX. Genes 2021, 12, 724. https://doi.org/10.3390/ genes12050724

Academic Editor: Sergi Puig

Received: 5 April 2021

Accepted: 11 May 2021

Published: 13 May 2021

Publisher's Note: MDPI stays neutral with regard to jurisdictional claims in published maps and institutional affiliations.

Copyright: (c) 2021 by the authors. Licensee MDPI, Basel, Switzerland. This article is an open access article distributed under the terms and conditions of the Creative Commons Attribution (CC BY) license (https:// creativecommons.org/licenses/by/ $4.0 /)$.

\begin{abstract}
Agaricus bisporus secretes siderophore to uptake environmental iron. Siderophore secretion in $A$. bisporus was enabled only in the iron-free minimal medium due to iron repression of hapX, a transcriptional activator of siderophore biosynthetic genes. Aiming to produce siderophore using conventional iron-containing complex media, we constructed a recombinant strain of $A$. bisporus that escapes hapX gene repression. For this, the $A$. bisporus hapX gene was inserted next to the glyceraldehyde 3-phosphate dehydrogenase promoter (pGPD) in a binary vector, $\mathrm{pBGgHg}$, for the constitutive expression of hapX. Transformants of A. bisporus were generated using the binary vector through Agrobacterium tumefaciens-mediated transformation. PCR and Northern blot analyses of the chromosomal DNA of the transformants confirmed the successful integration of pGPDhapX at different locations with different copy numbers. The stable integration of pGPD-hapX was supported by PCR analysis of chromosomal DNA obtained from the 20 passages of the transformant. The transformants constitutively over-expressed hapX by 3- to 5-fold and sidD, a key gene in the siderophore biosynthetic pathway, by 1.5- to 4-fold in mRNA levels compared to the wild-type strain (without $\mathrm{Fe}^{3+}$ ), regardless of the presence of iron. Lastly, HPLC analysis of the culture supernatants grown in minimal medium with or without $\mathrm{Fe}^{3+}$ ions presented a peak corresponding to iron-chelating siderophore at a retention time of $5.12 \mathrm{~min}$. The siderophore concentrations of the transformant $\mathrm{T} 2$ in the culture supernatant were 9.3 -fold $\left(-\mathrm{Fe}^{3+}\right)$ and 8-fold $\left(+\mathrm{Fe}^{3+}\right)$ higher than that of the wild-type $A$. bisporus grown without $\mathrm{Fe}^{3+}$ ions, while no siderophore was detected in the wildtype supernatant grown with $\mathrm{Fe}^{3+}$. The results described here demonstrate the iron-independent production of siderophore by a recombinant strain of $A$. bisporus, suggesting a new application for mushrooms through molecular biological manipulation.
\end{abstract}

Keywords: Agaricus bisporus; transformation; siderophore; expression

\section{Introduction}

Iron is an essential trace element that combines with proteins or small organic molecules involved in various oxidation-reduction reactions in living organisms. Due to the scarcity of iron in nature, microorganisms secure iron by secreting siderophores and absorbing them back into the cells following the adsorption of environmental iron [1]. Siderophores are small organic iron chelators that preferentially bind to $\mathrm{Fe}^{3+}$ ions through the formation of a coordination complex. They are classified by the ligand structure as carboxylates, hydroxamates, catecholates, and mixed types [2]. Siderophores, including enterobactin (catecholate), desferrioxamine (hydroxamate), and pyoverdine (mixed type), are known to be produced by bacteria [3], whereas hydroxamate siderophores, such as ferrichromes, fusarinine $C$, and triacetylfusarinine $C$ (TAFC), are the major siderophores in fungi $[1,4]$.

The fungal hydroxamate siderophores are synthesized by the activity of the nonribosomal peptide synthetase complex (NRPS). In Aspergillus fumigatus, SidC is involved in the biosynthesis of ferrichromes using $\mathrm{N}^{5}$-acetyl- $\mathrm{N}^{5}$-hydroxy-L-ornithine, glycine, and 
serine as precursors, where SidD catalyzes the condensation of three molecules of $\mathrm{N}^{5}$ anhydromevalonyl- $\mathrm{N}^{5}$-hydroxy-L-ornithine to produce fusarinine $\mathrm{C}$ and TAFC [1]. Basidiomycetes also have shown to contain similar NRPSs. Sid2 and Fso1 in Ustilago maydis [5] and Omphalotus olearius [6], respectively, are NRPSs homologous to SidC in A. fumigatus, whereas CsNPS2 in Ceriporiopsis subvermispora, NPS1 in Trametes versicolor, and the gene product of EAU88504 in Coprinopsis cinerea are thought to be homologous to SidD as they show similar domain arrangement [7]. Agaricus bisporus is reported to produce hydroxamate siderophores, such as ferrichrome, defferri-des(diserylglycyl) ferrirhodin, and fusarinine C [8], accordingly, and putative SidC and SidD homologues are found from the genome information of $A$. bisporus as described in the present study.

The expression of genes involved in the siderophore biosynthetic pathway is tightly regulated by the transcription factor hap $X$, which positively regulates the expression of sid genes and represses genes involved in iron-consuming pathways under iron-starvation conditions in A. fumigatus [9]. The expression of hapX is down-regulated by another transcription factor, sre $A$, under sufficient iron conditions [10,11]. Study on iron metabolism in basidiomycetes is rare. However, hapX and cir1, a homologue of sreA, in Cryptococcus neoformans have been extensively studied in relation to virulence in humans $[12,13]$. Similar to the ascomycetes, hapX in C. neoformans represses iron utilization and promotes iron uptake and cir 1 expression under iron starvation conditions $[12,13]$. Therefore, the deprivation of iron is a prerequisite for the expression of hap $X$ and thus for the production of siderophore in fungi.

Siderophores have multiple applications in agriculture as plant growth promotors and pathogen control agents, as well as in the removal of contaminated heavy metal ions [14]. In medicinal applications, siderophores are employed to treat diseases associated with iron overload [15]. Certain siderophores show antimicrobial activities against pathogenic bacteria, though siderophores mostly act as virulence factors for many pathogens [16-18]. Drug delivery through siderophore receptors after the formation of siderophore-drug complex may be a new strategy to deliver drugs that have permeability-mediated drug resistance [19]. Additionally, ferrichrome produced by Lactobacillus casei has been reported to show anticancer activity against colon cancer in a mouse model [20].

In the present study, we assess the potential of $A$. bisporus, a representative edible mushroom, as a host system for the production of biological molecules such as siderophores. However, A. bisporus, like other fungi, secreted siderophores only in the absence of iron, meaning that the production medium should be an iron-free minimal medium. To overcome this problem, we generated transformant strains of $A$. bisporus that express hapX, a master transcription factor for sid gene expression, using the constitutive glyceraldehyde 3-phosphate dehydrogenase promoter (pGPD).

\section{Materials and Methods}

\subsection{Strains and Culture Conditions}

A. bisporus NH1 was obtained from the National Institute of Horticultural and Herbal Science, Rural Development Administration (RDA; Eomsung, Korea). The mushroom strain was grown at $25^{\circ} \mathrm{C}$ on compost-potato dextrose agar (C-PDA), in which PDA (Oxoid, Basingstoke, UK) was supplemented with $200 \mathrm{~mL}$ of compost extract per litter. For the liquid culture, compost-potato dextrose broth (C-PDB) was prepared by supplementing the compost extract $(200 \mathrm{~mL} / \mathrm{L})$ with potato dextrose broth (Oxoid, Basingstoke, UK). The compost extract for the preparation of both media was prepared as follows: rice straw compost was suspended in water $(100 \mathrm{~g} / \mathrm{L})$, left for a day at room temperature, autoclaved for $40 \mathrm{~min}$ at $121^{\circ} \mathrm{C}$, then filtered using a Miracloth (Sigma-Aldrich, St. Louis, MO, USA).

\subsection{Construction of $p B G g H g$-hapX Vector}

The hapX gene sequence in A. bisporus was retrieved from the MycoCosm genome database (https:/ / mycocosm.jgi.doe.gov / Agabi_varbisH97_2/Agabi_varbisH97_2.home. html, accessed on 16 August 2019) by BLASTP analysis using A. fumigatus HapX protein 
(XP_747952.1) as a query sequence. The retrieved HapX protein contained a conserved Hap2/3/5 binding domain in front of the bZIP domain similar to A. fumigatus HapX protein (Supplementary Figure S1). Homologous gene sequences to A. fumigatus sidC and sidD were also retrieved under the gene accession numbers NW_006267370.1 and NW_006267372.1, respectively, using a similar approach.

For the isolation of hapX gene, A. bisporus NH1 was grown in $100 \mathrm{~mL}$ of C-PDB for 10 days at $25{ }^{\circ} \mathrm{C}$. The genomic DNA was isolated from the harvested mycelia using a genomic DNA extraction kit (HiGene Genomic DNA Prep kit; BIOFACT, Daejeon, Korea). The A. bisporus hapX gene (GenBank Accession No. XM_006454360) was amplified from the purified genomic DNA using a specific primer set (Supplementary Table S1, hapX-F and hapX-R) and a PCR premix (nPfu-Forte; Enzynomics, Daejeon, Korea). The PCR reaction consisted of the initial denaturation at $95^{\circ} \mathrm{C}$ for $5 \mathrm{~min}$, followed by 25 cycles of denaturation at $95{ }^{\circ} \mathrm{C}$ for $30 \mathrm{~s}$, annealing at $60^{\circ} \mathrm{C}$ for $30 \mathrm{~s}$, and polymerization at $72{ }^{\circ} \mathrm{C}$ for $4 \mathrm{~min}$, and a final extension at $72{ }^{\circ} \mathrm{C}$ for $10 \mathrm{~min}$. The resulting amplicon contained SwaI and SpeI restriction sites at the $5^{\prime}$ - and $3^{\prime}$-ends of the hapX gene provided by the primers, respectively. The hapX amplicon was digested by SwaI and SpeI and inserted into the corresponding restriction sites in the $\mathrm{pBGgHg}$ vector [21] by replacing the $e G F P$ gene, generating pBGgHg-hapX (Supplementary Figure S2).

\subsection{Transformation of Agrobacterium tumefaciens AGL-1 with $p B G g H g$-hapX}

Agrobacterium tumefaciens AGL-1 was grown in $10 \mathrm{~mL}$ of LB (peptone $10 \mathrm{~g} / \mathrm{L}$, yeast extract $5 \mathrm{~g} / \mathrm{L}, \mathrm{NaCl} 5 \mathrm{~g} / \mathrm{L}$ ) at $28{ }^{\circ} \mathrm{C}$ until the optical density at $600 \mathrm{~nm}$ reached 0.6 . The bacterial cells were collected by centrifugation $(10,000 \times g, 10 \mathrm{~min})$. The cell pellet was washed with 1X TE buffer and resuspended in $2 \mathrm{~mL}$ of $10 \% \mathrm{LB}$ broth. Aliquots of the competent cells were stored at $-70^{\circ} \mathrm{C}$ until use. For the transformation, the competent cells $(250 \mu \mathrm{L})$ were mixed with $1 \mu \mathrm{g}$ of pBGgHg-hapX plasmid DNA by gentle pipetting and were kept on ice for $5 \mathrm{~min}$. After the incubation, the tube was placed in liquid nitrogen for $5 \mathrm{~min}$ and then transferred to a water bath $\left(37^{\circ} \mathrm{C}\right)$. After $5 \mathrm{~min}$ of incubation, $1 \mathrm{~mL}$ of LB broth was added and incubated for an additional $2 \mathrm{~h}$ at $28^{\circ} \mathrm{C}$ with vigorous agitation. The incubated cells were collected by centrifugation and were suspended in $0.2 \mathrm{~mL} \mathrm{LB}$ broth. The suspension was spread on LB agar containing $50 \mathrm{mg} / \mathrm{L}$ of kanamycin. The plate was incubated for 2 days at $28^{\circ} \mathrm{C}$ to obtain A. tumefaciens AGL-1 transformed with pBGgHg-hapX.

\subsection{Agrobacterium tumefaciens-Mediated Transformation of Agaricus bisporus}

A. bisporus was transformed by the A. tumefaciens-mediated transformation (ATMT) method [21] with slight modifications. For the transformation, $1 \mathrm{~mL}$ of freshly grown A. tumefaciens AGL-1 harboring pBGgHg-hapX was inoculated to $100 \mathrm{~mL}$ of LB broth and incubated at $28^{\circ} \mathrm{C}$ with agitation $(170 \mathrm{rpm})$ until the optical density at $600 \mathrm{~nm}$ reached 0.8 . The cells were collected by centrifugation $(10,000 \times g, 10 \mathrm{~min})$ and were resuspended in $100 \mathrm{~mL}$ of induction medium (IM), containing $2 \mathrm{~g} / \mathrm{L}$ glucose, $5 \mathrm{~mL} / \mathrm{L}$ glycerol, $1 \mathrm{~g} / \mathrm{L} \mathrm{NH}_{4} \mathrm{Cl}$, $0.3 \mathrm{~g} / \mathrm{L} \mathrm{MgSO}_{4}, 0.15 \mathrm{~g} / \mathrm{L} \mathrm{KCl}, 0.01 \mathrm{~g} / \mathrm{L} \mathrm{CaCl}_{2}, 2.5 \mathrm{mg} / \mathrm{L} \mathrm{FeSO}_{4}, 0.2 \mathrm{mM}$ acetosyringone, $40 \mathrm{mM}$ MES buffer ( $\mathrm{pH} 5.3$ ), and $50 \mathrm{mg} / \mathrm{L}$ kanamycin. The cell suspension was incubated for $6 \mathrm{~h}$ at $25^{\circ} \mathrm{C}$. For the infection of A. tumefaciens to A. bisporus, pieces of gill tissue $(1 \mathrm{~mm})$ were cut from the fruiting body of $A$. bisporus NH1 and were co-incubated in the bacterial culture for $15 \mathrm{~min}$. The infected gill tissues were transferred onto IM agar (IM with $15 \mathrm{~g} / \mathrm{L}$ agar). After 3 days of incubation at $25^{\circ} \mathrm{C}$, the gill tissues were transferred to the first selection medium (C-PDA supplemented with $150 \mathrm{mg} / \mathrm{L}$ cefotaxime, $100 \mathrm{mg} / \mathrm{L}$ kanamycin, $25 \mathrm{mg} / \mathrm{L}$ chloramphenicol, gentamycin $100 \mathrm{mg} / \mathrm{L}$, and $30 \mathrm{mg} / \mathrm{L}$ hygromycin B). After 10 days of incubation at $25^{\circ} \mathrm{C}$, the tissues showing filamentous hyphal growth were transferred to the second selection medium (C-PDA with $50 \mathrm{mg} / \mathrm{L}$ hygromycin B). The mycelia outgrowing on the second selection medium upon prolonged incubation at $25^{\circ} \mathrm{C}$ were cut out from the agar medium and were subjected to further analysis. 


\subsection{PCR and Real-Time PCR Analyses of the A. bisporus Transformants}

The transformants of $A$. bisporus obtained from ATMT were analyzed by PCR using primer sets targeting an internal sequence region in the $h p h$ gene (731 bp; hph-F and hph-R) and a sequence region ranging from $\mathrm{pGPD}$ to the internal hapX sequence (725 bp; Pgpd-F and hapXin-R) (Figure 1a and Supplementary Table S1). The PCR conditions were the same as those described above, except for the polymerization time ( $30 \mathrm{~s}$ in this case). The expression of the hapX gene in the transformants was investigated by quantitative real-time PCR (qPCR) analysis. For the qPCR, $1 \mathrm{~mL}$ of actively grown mycelia in C-PDB were inoculated in $50 \mathrm{~mL}$ of minimal medium $\left(\mathrm{KCl} 0.2 \mathrm{~g} / \mathrm{L}, \mathrm{KH}_{2} \mathrm{PO}_{4} 0.14 \mathrm{~g} / \mathrm{L}, \mathrm{Na}_{2} \mathrm{HPO}_{4} \cdot 12 \mathrm{H}_{2} \mathrm{O}\right.$ $1.9 \mathrm{~g} / \mathrm{L}, \mathrm{CaCl}_{2} \cdot 2 \mathrm{H}_{2} \mathrm{O} 0.27 \mathrm{~g} / \mathrm{L}, \mathrm{MgSO}_{4} \cdot 7 \mathrm{H}_{2} \mathrm{O} 0.2 \mathrm{~g} / \mathrm{L}, \mathrm{ZnSO}_{4} \cdot 7 \mathrm{H}_{2} \mathrm{O} 2 \mathrm{mg} / \mathrm{L}, \mathrm{CuSO}_{4} \cdot 6 \mathrm{H}_{2} \mathrm{O}$ $0.1 \mathrm{mg} / \mathrm{L}, \mathrm{MnSO}_{4} \cdot \mathrm{H}_{2} \mathrm{O} 0.02 \mathrm{mg} / \mathrm{L},\left(\mathrm{NH}_{4}\right)_{6} \mathrm{Mo}_{7} \mathrm{O}_{24} \cdot 4 \mathrm{H}_{2} \mathrm{O} 0.02 \mathrm{mg} / \mathrm{L}, \mathrm{H}_{3} \mathrm{BO}_{3} 0.01 \mathrm{mg} / \mathrm{L}$, glucose $30 \mathrm{~g} / \mathrm{L}$, yeast extract $5 \mathrm{~g} / \mathrm{L}, \mathrm{pH} 6.8$ ) with or without $10 \mu \mathrm{M} \mathrm{FeCl}_{3}$. The culture was incubated for a week at $25^{\circ} \mathrm{C}$. The harvested mycelia were subjected to total RNA extraction. Total RNA was extracted using an RNeasy Plant Mini Kit (Qiagen, Hilden, Germany) from the mycelial powder $(0.1 \mathrm{~g})$, which was prepared by grinding with a pestle and mortar after freezing in liquid nitrogen. The extracted RNA was subjected to cDNA synthesis using a TOPscript cDNA Synthesis Kit (Enzynomics, Daejeon, Korea), followed by qPCR using FastStart Universal SYBR Green Master (Sigma-Aldrich) and Lightcycler Nano (Roche, Germany). The primers used for qPCR are shown in Supplementary Table S1. The qPCR results were analyzed using the expression of the $\beta$-tubulin gene as a reference. Relative gene repression was calculated using the $2^{-\Delta \Delta C q}$ value. All data were obtained in triplicate from three independent experiments. The statistical significance between data sets was analyzed using a one-way ANOVA test.

\subsection{Southern Blot Analysis with DIG-Labeling}

Genomic DNA $(20 \mu \mathrm{g})$ was digested with SpeI and AgeI for $24 \mathrm{~h}$ at $37^{\circ} \mathrm{C}$. The digested samples were subjected to agarose gel electrophoresis in $0.8 \%$ agarose gel $(15 \mathrm{~cm} \times 15 \mathrm{~cm})$ at $30 \mathrm{~V}$ for $18 \mathrm{~h}$, followed by $50 \mathrm{~V}$ for $3 \mathrm{~h}$. A digoxigenin (DIG)-labeled DNA marker (DNA molecular weight marker III, Roche, Germany) was run together for the size analysis. The DNA fragments in the agarose gel were transferred onto a nylon membrane (Amersham hybond ${ }^{\mathrm{TM}_{-}} \mathrm{N}^{+}$nylon membrane, GE Healthcare, Chicago, IL, USA) using standard blotting methods. After the transfer, the DNA fragments on the membrane were cross-linked using CL-1000 Ultraviolet Crosslinker (Spectrum chemical, New Brunswick, NJ, USA). The nylon membrane was subjected to hybridization with a $10 \mathrm{ng} / \mathrm{mL}$ DIG-labeled probe specific to the hapX gene. The DIG-labeled hapX probe was generated by PCR using hapX-probe-fwd and hapX-probe-rev primers (Supplementary Table S1) followed by DIG labeling using a labeling kit (Random Primed DNA Labeling Kit, Roche, Rotkreuz, Switzerland). The DIGlabeled DNA was visualized by the NBT/BCIP reaction after binding with $150 \mathrm{mU} / \mathrm{mL}$ of Anti-DIG-AP conjugate (Roche, Rotkreuz, Switzerland).

\subsection{HPLC Analysis}

The mycelia of $A$. bisporus were grown in C-PDB for 10 days and were harvested by centrifugation $(1000 \times g, 10 \mathrm{~min})$. The collected mycelia were resuspended in minimal medium and further incubated for 3 days. The culture broth was obtained through filtration with a Miracloth (Sigma-Aldrich, St. Louis, MO, USA) followed by $3 \mathrm{M}$ filter paper. Final 1 $\mathrm{mM}$ of $\mathrm{FeCl}_{3}$ was added to the filtrate to convert siderophores to iron-bound form. The treated filtrate $(2 \mathrm{~mL})$ was subjected to a Sep-Pak C18 cartridge (Waters, Milford, MA, USA). The cartridge was washed with $10 \mathrm{~mL}$ of deionized water, and then the bound siderophore was eluted by $5 \mathrm{~mL}$ of methanol. The eluate was dried by a vacuum evaporator. The dried sample was dissolved in $0.5 \mathrm{~mL}$ of deionized water. The obtained sample $(20 \mu \mathrm{L})$ was subjected to HPLC analysis using an HPLC system (HP1050; Hewlett-Packard, Palo Alto, CA, USA) equipped with an HC-C18(2) column $(150 \times 4.6 \mathrm{~mm}$; Agilent, Santa Clara, CA, USA). Isocratic elution was performed with $0.1 \%$ triflouroacetic acid as a mobile phase at a flow rate of $0.6 \mathrm{~mL} / \mathrm{min}$. The chromatogram was monitored at $214 \mathrm{~nm}$. 


\subsection{Determination of Siderophore Activity by Chrome Azurol-S Assay}

Siderophore in the sample solution was determined using a modified chrome azurol-S (CAS) assay [22]. For the formulation of the CAS reagent, $0.75 \mathrm{~mL}$ of $2 \mathrm{mM}$ CAS was mixed with $1 \mathrm{~mL}$ of $10 \mathrm{mM} \mathrm{FeCl}_{3}$ (in $10 \mathrm{mM} \mathrm{HCl}$ ) and $0.6 \mathrm{~mL}$ of $10 \mathrm{mM}$ hexadecyltrimethylammonium (HDTMA). The final volume of the mixture was brought up to $10 \mathrm{~mL}$ with deionized water after the addition of $5 \mathrm{~mL}$ of $1 \mathrm{M}$ MES (pH5.6) to make the CAS reagent. For the determination of siderophore, the peak fraction from the HPLC analysis $(0.6 \mathrm{~mL})$ was treated with $60 \mu \mathrm{L}$ of 3\% $(w / v)$ 8-hydroxyquinoline (Sigma-Aldrich, St. Louis, MO, USA) in chloroform. The chloroform layer was removed after centrifugation $(10,000 \times g, 5 \mathrm{~min})$. The aqueous layer $(0.5 \mathrm{~mL})$ was mixed with the CAS reagent $(0.5 \mathrm{~mL})$ and $10 \mu \mathrm{L}$ of $0.2 \mathrm{M}$ sulfosalicylic acid. The reaction mixture was incubated for $1 \mathrm{~h}$ at $25^{\circ} \mathrm{C}$. The decrease in the absorbance at $650 \mathrm{~nm}\left(\mathrm{~A}_{650}\right)$ was monitored using a UV-vis spectrophotometer. The relative production of siderophore was calculated using the following equation.

$$
\text { Relative production }=\left(\frac{\mathrm{A}^{\max }-\mathrm{A}^{\text {sample }}}{\mathrm{A}^{\mathrm{max}}-\mathrm{A}^{\mathrm{min}}}\right) \times 100
$$

where $\mathrm{A}^{\max }$ stands for the $\mathrm{A}_{650}$ value without siderophore and $\mathrm{A}^{\mathrm{min}}$ for the $\mathrm{A}_{650}$ value at the saturated siderophore concentration. $\mathrm{A}^{\text {sample }}$ represents the $\mathrm{A}_{650}$ value in the presence of the siderophore sample.

\section{Results}

\subsection{Generation of Transformants for the Constitutive Expression of hapX}

After ATMT with pBGgHg-hapX, a total of 172 mycelial isolates grown out of the gill tissues on the selection medium were examined by PCR with primer sets targeting PGPDhapX and hph (Figure 1a). As a result, 42 isolates (24.4\%) were found to contain pGPD-hapX and $h p h$ as an indication of successful integration (Figure 1b). Next, the genomic DNA of 10 randomly selected transformants was subjected to Southern blot analysis to further confirm the genomic integration of pGPD-hapX. The DIG-labeled probe targeting the hapX gene detected a DNA band containing an endogenous hapX gene with a size of $15.5 \mathrm{~kb}$ (Figure 1c, arrow), as well as an integrated hapX gene of variable size in the transformants (Figure 1c). The transformants carried at least one additional copy of the hapX gene. The transformants, including T4, T7, T13, T18, T22, T23, and T24, were found to contain a single additional hapX gene of variable size in the genomic DNA fragment, whereas T1 and T15 had two additional copies of the hapX gene. The transformant $\mathrm{T} 2$ had four copies of the hapX gene, of which three were from the genomic integration of pGPD-hapX. 

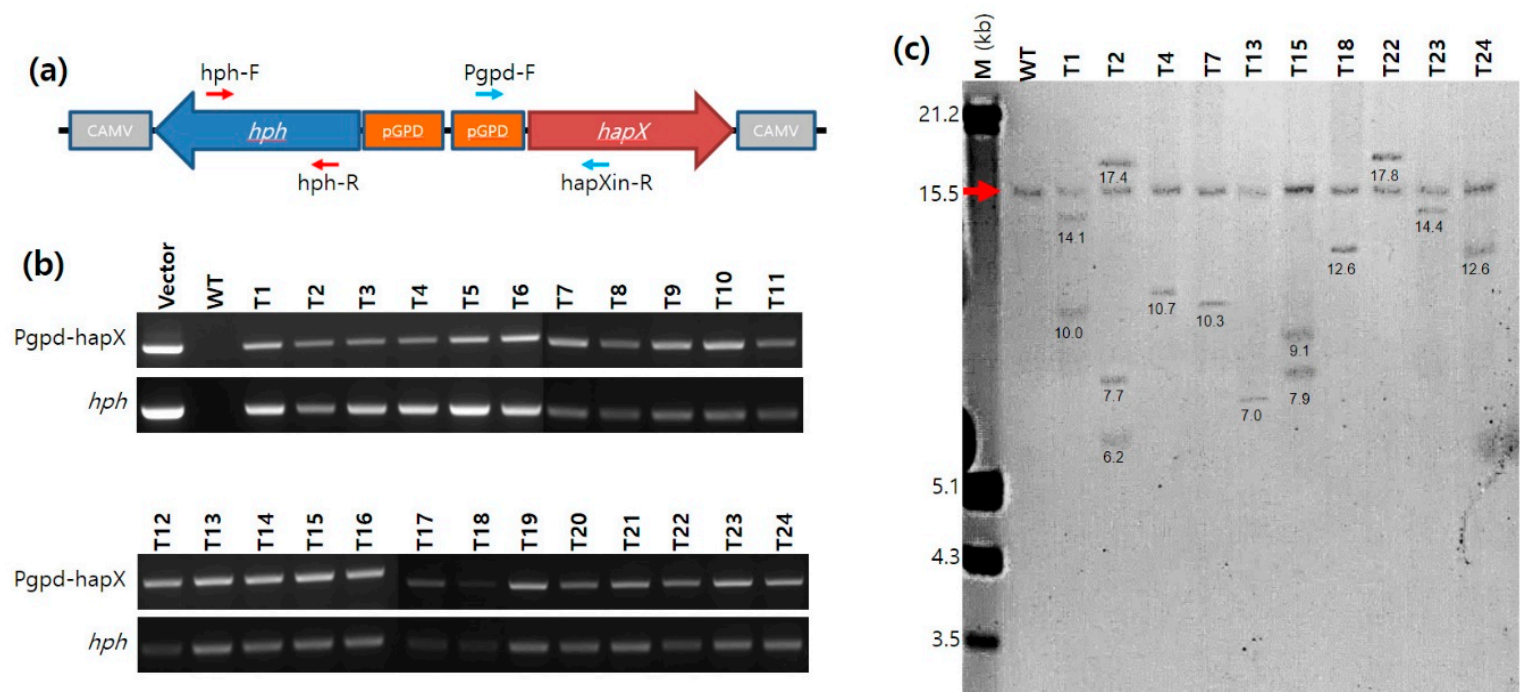

Figure 1. The transformation of Agaricus bisporus. (a) Gene arrangement of the integrating unit in pBGgHg-hapX. Red arrows and blue arrows indicate the positions of primers for the detection of $h p h$ and pGPD-hapX, respectively. CAMVs are CAMV poly(A) signals residing in front LB and RB of pBGgHg-hapX. (b) PCR analysis of the transformants. The amplicons were approximately $500 \mathrm{bp}$ for both targets. (c) Southern blot analysis of the transformants. Genomic DNA (20 $\mu \mathrm{g})$ was isolated from liquid cultures, digested with $A g e I$ and SacI, and probed with an $\sim 675$ bp DIG-labeled hapX gene sequence. Lanes; M, DNA molecular size marker (kb); WT, untransformed A. bisporus; T1 to T24, transformants. The red arrow indicates the original hapX gene fragment. Numbers under the DNA bands indicate the sizes of genomic DNA fragments.

Successive transfer of the transformants on C-PDA (hygromycin B-free) medium was performed to investigate the genetic stability of the integrated pGPD-hapX and hph genes in the host genome. The growing edge of mycelia was successively transferred to fresh C-PDA every 3 weeks. After 20 successive transfers, the presence of pGPD-hapX and $h p h$ genes in the genomic DNA of the transformants was examined by PCR with the primer sets described above. The PCR analysis revealed that the integrated DNA was stably maintained (Supplementary Figure S3). There was no difference in the growth characteristics between the wild-type (WT) and the transformants even after the twenty successive transfers (Supplementary Figure S3).

\subsection{Effect of Iron on the mRNA Expression of hapX}

The expression of hapX in the transformants was investigated by qPCR using total RNAs extracted from mycelial cells grown in minimal medium with or without $10 \mu \mathrm{M}$ $\mathrm{Fe}^{3+}$. The hapX gene expression in the WT was repressed in the presence of $\mathrm{Fe}^{3+}$ (Figure 2a), together with the repression of sidD, a downstream component of the hapX gene (Figure $2 b$ ). Removal of $\mathrm{Fe}^{3+}$ resulted in 6.1- and 7.9-fold increases in the hapX and sidD expression, respectively. In contrast, the presence of $\mathrm{Fe}^{3+}$ no longer repressed the expression of both genes in the four selected pGPD-hapX transformants because of the constitutive expression by the pGPD promoter. The transformants showed approximately 3- to 5-fold overexpression of hapX and 1.5- to 4-fold overexpression of sidD, independently of $\mathrm{Fe}^{3+}$, when compared with the corresponding gene expression in the WT grown in iron-free medium (Figure 2). Removal of $\mathrm{Fe}^{3+}$ resulted in slight but statistically insignificant changes in the gene expression levels among the transformants, except for T2, which showed 1.2- and 1.4-fold greater expression in hapX and sidD, respectively, in the absence of $\mathrm{Fe}^{3+}$. The multiple integrations of pGPD-hapX into the genomic DNA appeared to influence the hapX and sidD expression; however, the copy number did not linearly correlate with the gene expression level. The transformant $\mathrm{T} 2$, which contained three additional transgenic copies of the hapX gene, showed only 1.3-fold more hapX gene expression than T15, which had two additional copies of the hapX gene. Moreover, the expression level of sidD in T2 
was almost the same as that in T15. Notably, the sidD expression in T1, which has two additional hapX copies, was lower than that in T15.

(a)

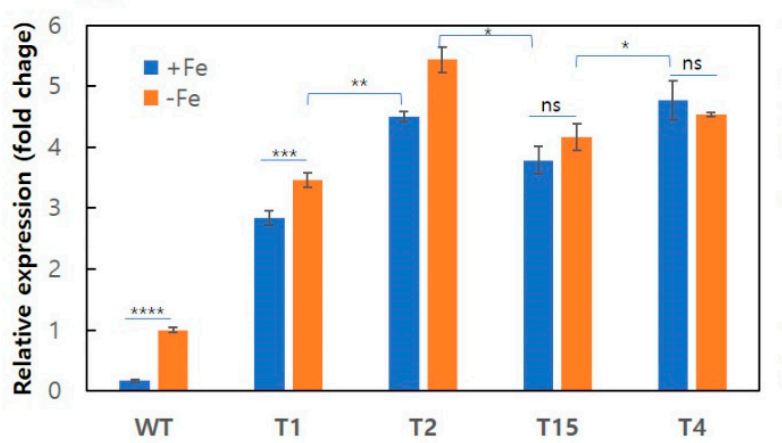

(b)

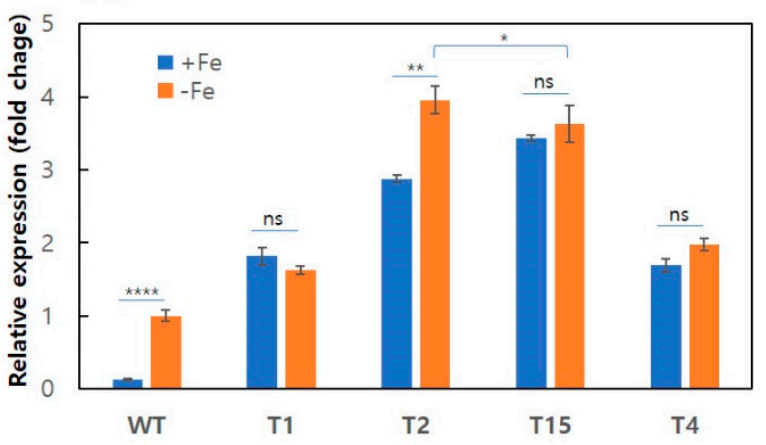

Figure 2. mRNA expression level comparison of transformants. Relative RNA expression of hapX (a) and sidD (b) in the wild-type (WT) and the transformants T1, T2, T3, and T4. Each strain was treated with $10 \mu \mathrm{M} \mathrm{FeCl}_{3}(+\mathrm{Fe})$ or was held in iron-free $(-\mathrm{Fe})$ conditions for a $24 \mathrm{~h}$ incubation period. Error bars indicate the standard deviations of the means. The statistical significance of the mean difference between samples is indicated on the bar using asterisks $\left({ }^{*}\right.$ for $p \leq 0.05,{ }^{* *}$ for $p \leq 0.01,{ }^{* * *}$ for $p \leq 0.001,{ }^{* * * *}$ for $p \leq 0.0001$, and ns for not significant).

\subsection{Production of Siderophore by the $p G P D$-hapX Transformants}

The culture supernatants of WT and T2 strains that were grown in minimal medium with or without $\mathrm{Fe}^{3+}$ were subjected to HPLC analysis to compare siderophore production. The wild-type strain showed only a small peak corresponding to siderophore at a retention time of $5.12 \mathrm{~min}$ from the culture broth without $\mathrm{Fe}^{3+}$ (Figure 3). HPLC analysis of the T2 strain revealed the presence of the same siderophore peak from both iron-free [T2 $(-\mathrm{Fe})]$ and iron-included [T2(+Fe)] culture supernatants of T2 (Figure 3). However, the concentration of siderophore produced from T2 was 9.3-fold and 8.0-fold higher for iron-free and ironincluded supernatants, respectively, than that from the wild-type, as compared by the peak area. The siderophore production was comparable to the expressed mRNA level of the hapX gene.

The iron-chelating activity of the siderophore in the peak fraction of HPLC was investigated by CAS assay. Deprivation of $\mathrm{Fe}^{3+}$ in the CAS-Fe $\mathrm{F}^{3+}$ complex could be monitored by the decrease in the absorbance at $650 \mathrm{~nm}$, as observed in the EDTA treatment (Supplementary Figure S4). Treatment of the peak fraction from WT $(-\mathrm{Fe})$ resulted in very little change in the CAS-Fe ${ }^{3+}$ spectrum because of low siderophore concentration (Figure 3c). However, the peak fraction from either $\mathrm{T} 2(-\mathrm{Fe})$ or $\mathrm{T} 2(+\mathrm{Fe})$ showed high $\mathrm{Fe}^{3+}$-chelating activity by removing the absorption peak at $650 \mathrm{~nm}$, as an indication of high siderophore production.

Next, we investigated the effects of $\mathrm{pH}$ and temperature on the mycelial growth and siderophore production of the WT and T2 in liquid culture. Both the WT and T2 showed better growth at $\mathrm{pH} 6-7$, although the mycelial growth was not affected greatly in the range of pH 5-7.5 (Figure 4). However, the siderophore production was highly dependent on $\mathrm{pH}$, having the highest production level near a $\mathrm{pH}$ of 7.0 for both WT and T2. The siderophore production of T2 was approximately 10-fold higher than that of the WT in the investigated $\mathrm{pH}$ range. Both the $\mathrm{WT}$ and $\mathrm{T} 2$ showed optimal growth at $25 \sim 30{ }^{\circ} \mathrm{C}$ with maximal siderophore production within the temperature range. Mycelial growth below or above this temperature range was decreased in both strains. It is notable that the iron-chelating activity observed in WT may come from iron-chelating metabolites, such as oxalate and citrate. 

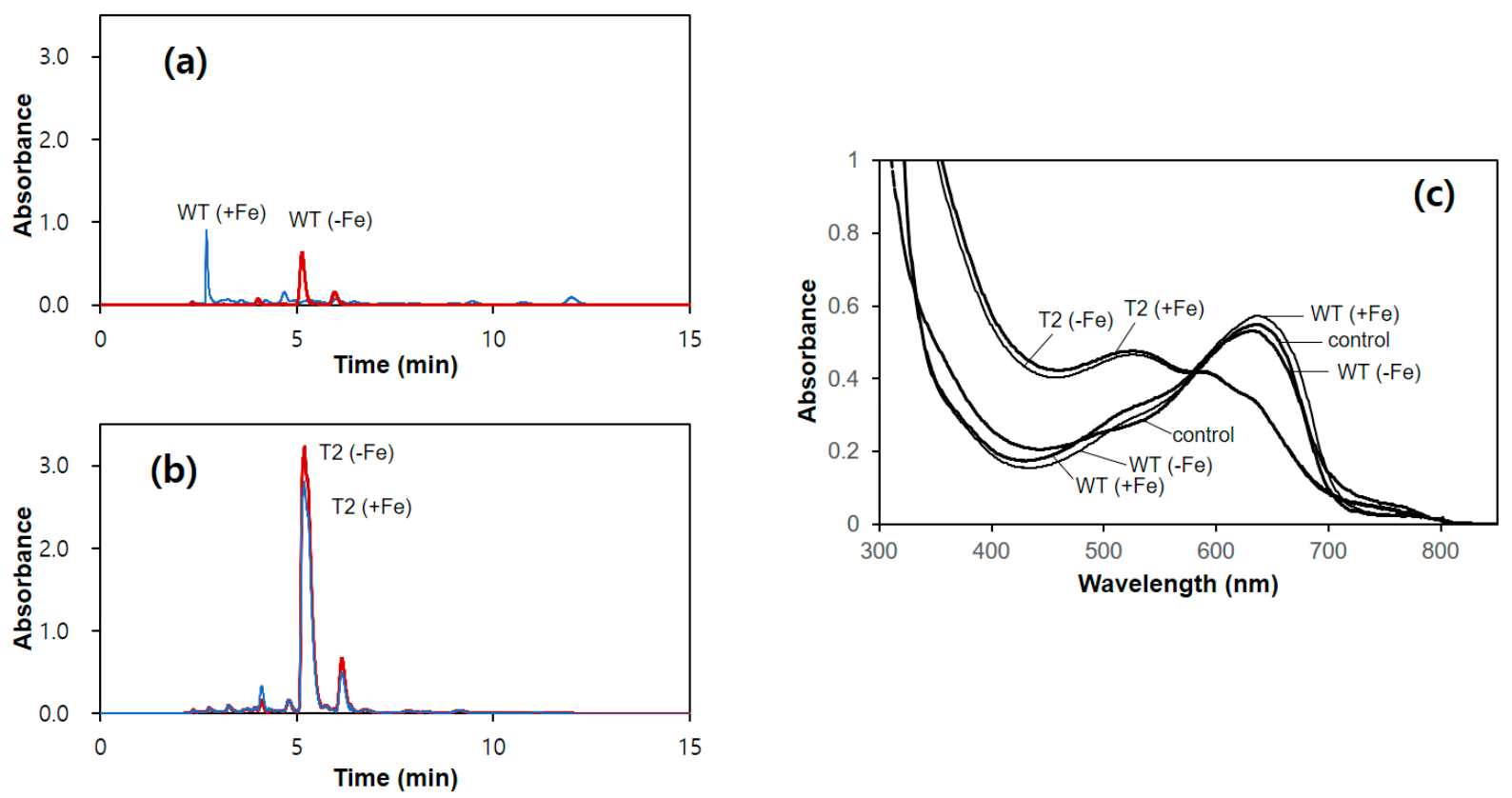

Figure 3. Production of siderophore by the wild-type and T2 strain. (a) HPLC analysis of the culture supernatant of the wild-type (WT) or the transformant (T2) grown in a minimal medium containing $10 \mu \mathrm{M} \mathrm{Fe}^{3+}$. (b) HPLC analysis of the culture supernatant of the wild type (WT) or the transformant (T2) grown in minimal medium without iron. (c) Modified chrome azurol-S (CAS) assay for the detection of siderophore. The peak fraction (5 min) from the HPLC analysis was subjected to a CAS assay.
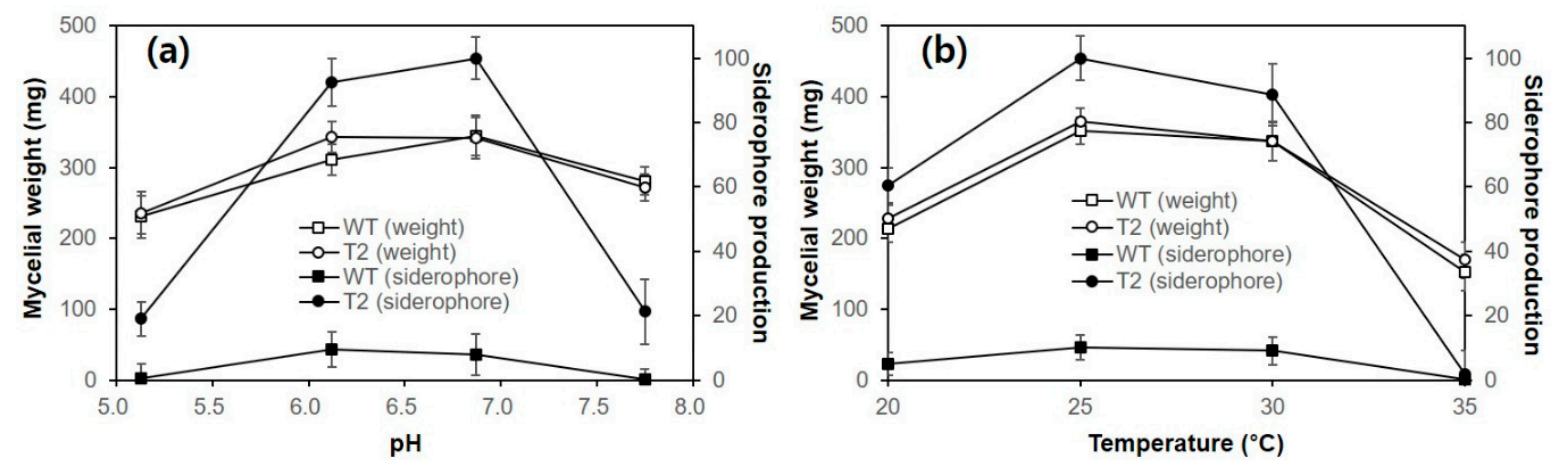

Figure 4. Effect of culture $\mathrm{pH}$ and temperature on the siderophore production and the mycelial growth of the wild-type (WT) and the transformant (T2). (a) Effect of $\mathrm{pH}$. The strains were grown in C-PDB (50 mL) with different $\mathrm{pH}$ values for 2 weeks at $25^{\circ} \mathrm{C}$. (b) Effect of temperature. The strains were grown in C-PDB $(50 \mathrm{~mL})$ for 2 weeks at different temperatures. Siderophore in the culture supernatant was analyzed by a CAS assay, and the mycelial mass was measured after drying at $60{ }^{\circ} \mathrm{C}$ for $24 \mathrm{~h}$. The siderophore productions shown here are the relative productions compared to the maximum values under the experimental conditions. Both experiments were carried out in triplicate, and the mean values are plotted with standard errors as error bars.

\section{Discussion}

Mushrooms mostly belonging to the phylum Basidiomycota are an important group of fungi due to their roles as decomposers in the ecosystem. Some of them, including A. bisporus, Lentinula edodes, Pleurotus ostreatus, and Flammulina velutipes, are mainly consumed as nutritious foods, while others, such as Ganoderma lucidum, Phellinus linteus, Inonotus obliquus, and Trametes versicolor, are used as sources of biologically active compounds [23]. Although they have a long history of human consumption, there have been few studies on the genetic (metabolic) engineering of basidiomycetes in order to use them as biological hosts to produce small organic compounds, despite the fact that they are 
equipped well with various metabolic pathways and diversified by their gene duplication and horizontal gene transfer [24].

A. bisporus is one of the best-studied commercial mushrooms in genetics and molecular biology [21,25-27], making it a good model system for the genetic engineering of mushrooms. In the present study, we demonstrated the successful transformation of $A$. bisporus to produce siderophore independently of iron, as normally, A. bisporus only produces siderophore in the absence of iron to acquire environmental iron. In filamentous fungi, sid genes involved in the siderophore biosynthesis are under the control of the main transcriptional activator, hapX, the expression of which is negatively controlled by ferrous ion [9]. For the constitutive expression of hapX, we isolated a hapX homolog and GPD promoter (pGPD) from the A. bisporus chromosomal DNA and performed genomic integration of pGPD-hapX through A. tumefaciens-mediated transformation. The transformation efficiency (24\%) was comparable to that which was previously reported (30-40\%) [21]. Southern blot analysis revealed that single-copy integration of $\mathrm{PGPD}$-hapX was prevalent; however, the transformants with 2-3 copies of pGPD-hapX integration were also observed, similar to a previous report on $\mathrm{pBGgHg}$ [21]. The multiple copies observed in certain transformants in this study do not imply multiple integrations to the chromosomes of a certain nucleus because A. bisporus can have multiple nuclei in the cytoplasm. Nonetheless, in contrast to this previous report, which failed to detect the expression of the eGFP gene [21], we observed the functional expression of hapX at the mRNA level (Figure 2) and also at the protein level, as deduced from the constitutive production of siderophore (Figure 3). This is conceivable because $h a p X$ originates from $A$. bisporus itself, thereby enabling normal mRNA processing and the use of host codons, in contrast to heterologous eGFP [21]. Additionally, we showed that integrated $\mathrm{PGPD}$-hapX is maintained stably through successive transfers in the absence of selective pressure.

A. bisporus has been known to produce three hydroxamate siderophores, including ferrichrome (FC), defferri-des(diserylglycyl) ferrirhodin (DDF), and fusarinine $\mathrm{C}(\mathrm{FsC})$, at the ratios of $10 \%, 30 \%$, and $60 \%$, respectively [8]. The first two siderophores are known to be synthesized by the NRPS activity of the sidC gene product using $\mathrm{N}^{5}$-acetyl-N ${ }^{5}-\mathrm{OH}-\mathrm{L}-\mathrm{Orn}$, glycine, and serine as precursors, whereas $\mathrm{FsC}$ is a condensation product comprised of three molecules of $\mathrm{N}^{5}$-anhydromevalonyl- $\mathrm{N}^{5}$-OH-L-Orn catalyzed by the NRPS encoded by sidD [1]. The true nature of the siderophore produced from the pGPD-hapX transformants was not identified; however, our RT-PCR analysis showed that only the sidD gene was transcribed in a hapX-dependent manner, while the expression of sidC was not observed (data not shown), suggesting that the siderophore produced in the present study is FsC.

Since mushrooms have mostly been consumed as fresh foods or medicines, research on their molecular genetic modification is very rare. However, considering the fact that mushrooms produce various organic molecules in their different developmental stages, they have great potential as host systems for the production of useful organic compounds. In this regard, our research provides a good example of how a common mushroom can be transformed into a producer of valuable organic compounds using genetic manipulation.

\section{Conclusions}

Iron inhibits siderophore biosynthesis in A. bisporus by repressing the hapX transcription factor. Using A. bisporus transformants that constitutively express hap $X$ through the GPD promoter, we demonstrate the iron-independent production of siderophore. The constitutive expression of hapX leads to the expression of sidD, an NRPS gene, which results in the production of siderophore in the iron-containing complex medium.

Supplementary Materials: The following are available online at https:/ / www.mdpi.com/article / 10.3390/genes12050724/s1, Figure S1: Domain structure of HapX proteins from different fungal species, Figure S2: Organization of binary vector pBGgHg-hapX, Figure S3: Genetic stability of the transformants. The transformants T1-T4 were repeatedly transferred to new media when the mycelia were fully grown. The presence of PGPD-hapX was investigated using PCR with the primers targeting pGPD-hapX and $h p h$, Figure S4: Effect of EDTA on UV-vis spectrum of CAS-Fe ${ }^{3+}$ complex. $^{2}$ 
(a) Spectral change at different concentrations of EDTA. (b) Concentration dependent change in the absorbance at $650 \mathrm{~nm}$, Table S1: Primers used in this study.

Author Contributions: Conceptualization, M.-S.K. and H.-S.R.; methodology, M.-S.K. and H.-S.R.; validation, M.-S.K. and H.-S.R.; formal analysis, M.-S.K.; data curation, H.-S.R.; writing-original draft preparation, M.-S.K. and H.-S.R.; writing-review and editing, H.-S.R.; funding acquisition, H.-S.R. All authors have read and agreed to the published version of the manuscript.

Funding: This work was supported by grants from the Cooperation Research Program for Agriculture Science and Technology Development (Project No. PJ01368102) and the New Breeding Technologies Development Program (Project No. PJ01516502), Rural Development Administration (RDA), Republic of Korea.

Acknowledgments: We are grateful to Jae-Yeon Kim and Min-Ju Kim at the Division of Life Sciences, GNU, for their technical help with the Southern blot analysis.

Conflicts of Interest: The authors declare no conflict of interest.

\section{References}

1. Haas, H. Fungal siderophore metabolism with a focus on Aspergillus fumigatus. Nat. Prod. Rep. 2014, 31, 1266-1276. [CrossRef] [PubMed]

2. Aznar, A.; Dellagi, A. New insights into the role of siderophores as triggers of plant immunity: What can we learn from animals? J. Exp. Bot. 2015, 66, 3001-3010. [CrossRef]

3. Hider, R.C.; Kong, X. Chemistry and biology of siderophores. Nat. Prod. Rep. 2010, 27, 637-657. [CrossRef]

4. Van der Helm, D.; Winkelmann, G. Hydroxamates and polycarbonates as iron transport agents (siderophores) in fungi. In Metal Ions in Fungi; Winkelmann, G., Winge, D.R., Eds.; Decker: New York, NY, USA, 1994; pp. 39-148.

5. Winterberg, B.; Uhlmann, S.; Linne, U.; Lessing, F.; Marahiel, M.A.; Eichhorn, H.; Kahmann, R.; Schirawski, J. Elucidation of the complete ferrichrome A biosynthetic pathway in Ustilago maydis. Mol. Microbiol. 2010, 75, 1260-1271. [CrossRef] [PubMed]

6. Welzel, K.; Eisfeld, K.; Antelo, L.; Anke, T.; Ankem, H. Characterization of the ferrichrome A biosynthetic gene cluster in the homobasidiomycete Omphalotus olearius. FEMS Microbiol. Lett. 2005, 249, 157-163. [CrossRef]

7. Brandenburger, E.; Gressler, M.; Leonhardt, R.; Lackner, G.; Habel, A.; Hertweck, C.; Brock, M.; Hoffmeister, D. A highly conserved basidiomycete peptide synthetase produces a trimeric hydroxamate siderophore. Appl. Environ. Microbiol. 2017, 83, e01478-17. [CrossRef]

8. Eng-Wilmot, D.L.; Adjimani, J.P.; van der Helm, D. Siderophore-mediated iron (III) transport in the mycelia of the cultivated fungus, Agaricus bisporus. J. Inorg. Biochem. 1992, 48, 183-195.

9. Schrettl, M.; Haas, H. Iron homeostasis-Achilles' heel of Aspergillus fumigatus? Curr. Opin. Microbiol. 2011, 14, 400-405. [CrossRef]

10. Lopez-Berges, M.S.; Capilla, J.; Turra, D.; Schafferer, L.; Matthijs, S.; Jochl, C.; Cornelis, P.; Guarro, J.; Haas, H.; Di Pietro, A. HapX-mediated iron homeostasis is essential for rhizosphere competence and virulence of the soilborne pathogen Fusarium oxysporum. Plant Cell 2012, 24, 3805-3822. [CrossRef]

11. Gsaller, F.; Hortschansky, P.; Beattie, S.R.; Klammer, V.; Tuppatsch, K.; Lechner, B.E.; Rietzschel, N.; Werner, E.R.; Vogan, A.A.; Chung, D.; et al. The Janus transcription factor HapX controls fungal adaptation to both iron starvation and iron excess. EMBO J. 2014, 33, 2261-2276. [CrossRef] [PubMed]

12. Jung, W.H.; Saikia, S.; Hu, G.; Wang, J.; Fung, C.K.; D'Souza, C.; White, R.; Kronstad, J.W. HapX positively and negatively regulates the transcriptional response to iron deprivation in Cryptococcus neoformans. PLoS Pathog. 2010, 6, e1001209. [CrossRef]

13. Do, E.; Cho, Y.J.; Kim, D.; Kronstad, J.W.; Jung, W.H. A transcriptional regulatory map of iron homeostasis reveals a new control circuit for capsule formation in Cryptococcus neoformans. Genetics 2020, 215, 1171-1189. [CrossRef]

14. Saha, M.; Sarkar, S.; Sarkar, B.; Sharma, B.K.; Bhattacharjee, S.; Tribedi, P. Microbial siderophores and their potential application: A review. Environ. Sci. Pollut. Res. 2016, 23, 3984-3999. [CrossRef]

15. Rosenthal, A.; Nathan, D.G. Continuous subcutaneous administration of deferoxamine in patients with iron overload. N. Engl. J. Med. 1977, 297, 418-423.

16. Ratledge, C. Iron metabolism and infection. Food Nutr. Bull. 2007, 28 (Suppl. S4), S515-S523. [CrossRef] [PubMed]

17. Thompson, M.G.; Corey, B.W.; Si, Y.; Craft, D.W.; Zurawski, D.V. Antibacterial activities of iron chelators against common nosocomial pathogens. Antimicrob. Agents Chemother. 2012, 56, 5419-5421. [CrossRef]

18. De Léséleuc, L.; Harris, G.; KuoLee, R.; Chen, W. In vitro and in vivo biological activities of iron chelators and gallium nitrate against Acinetobacter baumannii. Antimicrob. Agents Chemother. 2012, 56, 5397-5400. [CrossRef] [PubMed]

19. Huang, Y.; Jiang, Y.; Wang, H.; Wang, J.; Shin, M.C.; Byun, Y.; He, H.; Liang, Y.; Yang, V.C. Curb challenges of the "Trojan Horse" approach: Smart strategies in achieving effective yet safe cell-penetrating peptide-based drug delivery. Adv. Drug Deliv. Rev. 2013, 65, 1299-1315. [CrossRef] [PubMed]

20. Konishi, H.; Fujiya, M.; Tanaka, H.; Ueno, N.; Moriichi, K.; Sasajima, J.; Ikuta, K.; Akutsu, H.; Tanabe, H.; Kohgo, Y. Probioticderived ferrichrome inhibits colon cancer progression via JNK-mediated apoptosis. Nat. Commun. 2016, 7, 12365. [CrossRef] 
21. Chen, X.; Stone, M.; Schlagnhaufer, C.; Romaine, C.P. A fruiting body tissue method for efficient Agrobacterium-mediated transformation of Agaricus bisporus. Appl. Environ. Microbiol. 2000, 66, 4510-4513. [CrossRef]

22. Alexander, D.B.; Zuberer, D.A. Use of chrome azurol $S$ reagents to evaluate siderophore production by rhizosphere bacteria. Biol. Fertil. Soils 1991, 12, 39-45. [CrossRef]

23. De Silva, D.D.; Rapior, S.; Sudarman, E.; Stadler, M.; Xu, J.; Alias, S.A.; Hyde, K.D. Bioactive metabolites from macrofungi: Ethnopharmacology, biological activities and chemistry. Fungal Divers. 2013, 62, 1-40. [CrossRef]

24. Wisecaver, J.H.; Slot, J.C.; Rokas, A. The evolution of fungal metabolic pathways. PLoS Genet. 2014, 10, e1004816. [CrossRef] [PubMed]

25. Van de Rhee, M.D.; Graca, P.M.A.; Huizing, H.J.; Mooibroek, H. Transformation of the cultivated mushroom, Agaricus bisporus, to hygromycin B resistance. Mol. Gen. Genet. 1996, 250, 252-258. [CrossRef]

26. Morin, E.; Kohler, A.; Baker, A.R.; Foulongne-Oriol, M.; Lombard, V.; Nagye, L.G.; Ohm, R.A.; Patyshakuliyeva, A.; Brun, A.; Aerts, A.L.; et al. Genome sequence of the button mushroom Agaricus bisporus reveals mechanisms governing adaptation to a humic-rich ecological niche. Proc. Natl. Acad. Sci. USA 2012, 109, 17501-17506. [CrossRef] [PubMed]

27. Sonnenberg, A.S.M.; Gao, W.; Lavrijssen, B.; Hendrickx, P.; Sedaghat-Tellgerd, N.; Foulongne-Oriol, M.; Kong, W.S.; Schijlen, E.; Baars, J.; Visser, R. A detailed analysis of the recombination landscape of the button mushroom Agaricus bisporus var. bisporus. Fungal Genet. Biol. 2016, 93, 35-45. [CrossRef] [PubMed] 